\title{
The influence of the measurement errors on the Brutsaefrt and Nieber analysis of flow recession curves
}

\author{
Jacek Kurnatowski ${ }^{1, *}$ \\ ${ }^{1}$ Department of Hydroengineering, West Pomeranian University of Technology in Szczecin, Al. Piastów 50, 70-311 Szczecin, Poland
}

\begin{abstract}
The paper presents the problem of mathematical form of the hydrological recession in rivers when using conceptual models to describe the catchment behavior. One of the well-known ways of this analysis is the Brutsaert and Nieber method which is based on graphical comparison of flow values and its derivatives. It has been proved that the classical interpretation of these results does not reflect the possible influence of measurement errors which strongly affects the flow derivatives values.
\end{abstract}

\section{Introduction}

Hydrometric measurements in rivers are usually carried out in fixed cross-sections, called river gauge stations, and concern mainly stages and flows. Stages, i.e. water surface elevations above some arbitrarily assumed comparative level ("zero" of a gauge) in most cases are measured with vertical rods (water level gauges) with the accuracy of $0.01 \mathrm{~m}$. In practice, this accuracy is difficult to achieve due to some instabilities of the water surface position (short waves). This problem does not exist when using stage recorders equipped with relevant damping devices; nevertheless, the majority of recorded stage values, in particular in small watercourses, is still gathered by visual observations of the gauges.

The problem of river flow measurements is much more difficult and complicated. The flow is defined as an integral of water velocities over a cross-section area; thus, its determination requires a prior measurements of velocities in a set of points within the cross-section. Although nowadays it is done relatively easily by the application of modern measurement devices, like ADCP (Acoustic Doppler Current Profiler), for many decades these measurements used to be carried out by e.g. hydrometric propellers, what was time- and effort consuming process. In order to simplify the process of gathering rivers' flow values, the standard procedure was (and still is) the application of the stage-flow relation curve, determined on the basis of prior measurements. Such a relation should be periodically verified and amended if necessary; unfortunately, in a number of cases these relations are outdated (e.g. by changes of the cross-sections shape which took place in the meantime) and biased. Therefore, the flow values being used by hydrologists as raw data sets are biased by the outdated stage-flow relations as well as errors resulting from inaccuracy of these relations and additionally subject to errors of stage measurements.

\section{The flow recession curves and its role in hydrological analysis}

The river flow recession curves are usually defined as flow hydrographs (graphs of flow versus time) in periods when neither precipitations nor additional supplies of an aquifer from external sources take place. Therefore, the flow in a river is supplied only by the groundwater resources of the saturated zone since no surface runoff is present. For accuracy, it should be mentioned that despite the lack of precipitation and surface runoff a supply from the vadose zone (aerated layer) can be present since this kind of a recipient supply (still unrecognized enough) is delayed in relation to surface conditions; nevertheless, this factor usually has been neglected, in particular at lowland areas. Thus, as a one-factor simple case, the recession curves are often used as a source of identification of various catchment supply models, in particular conceptual ones.

The conceptual models concerning the catchment behavior are usually presented in a form of a hydraulic system with analogous principle of work. In particular, these systems may be presented as single reservoirs, where the outflow (river supply) intensity is related to the present storage within the reservoir and the mass balance condition is valid. This type of analogy is called the lumped storage models [1].

The simplest lumped storage model is the linear one, where the outflow $Q\left[\mathrm{~m}^{3} \mathrm{~s}^{-1}\right]$ is directly proportional to the storage $S\left[\mathrm{~m}^{3}\right]$, i.e.:

\footnotetext{
*Corresponding author: jkurnatowski@ zut.edu.pl
} 


$$
Q=\alpha S
$$

Introducing the continuity equation for this reservoir including any external supply (inflow) $I\left[\mathrm{~m}^{3} \mathrm{~s}^{-1}\right]$ :

$$
\frac{d S}{d t}=I-Q
$$

Eqs. (1) and (2) yield:

$$
\frac{d Q}{d t}+\alpha Q-\alpha I=0
$$

Eq. (3) has a solution:

$$
Q(t)=e^{-\alpha t}\left[Q(0)+\alpha \int_{0}^{t} I(t) e^{\alpha t} d t\right]
$$

which, in the case of the recession $(I=0)$, is simplified to the single exponential curve:

$$
Q(t)=Q(0)_{e}^{-\alpha t}
$$

Eq. (5) is the most popular and most widespread in hydrological handbooks standard recession curve. Nevertheless, it is worth noting that the linear model is only a special case among the group of nonlinear ones, where:

$$
Q=\alpha S^{\beta}
$$

In the case of recession Eq. (6) leads to the following differential equation:

$$
\frac{d Q}{d t}+a Q^{b}=0
$$

with a solution $($ at $\beta \neq 1)$ :

$$
Q(t)=\left[Q(0)^{1-b}-a(1-b) t\right]^{\frac{1}{1-b}}
$$

where:

$$
a=\alpha^{\frac{1}{\beta}} \beta ; b=\frac{2 \beta-1}{\beta} .
$$

The discussion about the appropriate (linear or nonlinear) form of the lumped storage models for recession curves has lasted for many decades, almost since the fundamental work of Boussinesq describing the unsteady flow in a saturated zone of the porous medium [2]. When analyzing the history of this concept development it is impossible not to notice the slow but systematic and quite clear trend based on consisting in moving from a priori and seemingly unmistakable solutions to a situation in which more questions are asked than answers obtained. Werner and Sundquist [3] presented the recession curves as a sum of three exponential functions with different coefficients; Toebes with his collaborators defined a set of possible equations of recession curves including the simple exponential, double exponential and hyperbolic
$[4,5]$ formulating conditions under which a certain type of curve could be expected. The more contemporary papers present different opinions as well: for instance, Tallaksen [1] states that simple linear model does not satisfactory represent the recession curve over a wide range of flows. Wittenberg [6] is of a similar opinion claiming that more realistic alternative to linear reservoir function is to assume $b=2$. Supporters of the model's nonlinearity are also Aksoy and Wittenberg [7] and Ali et al. [8]. De Rooij [9] argues that the linearity of the relation is possible only at coincidence of favorable circumstances, including constant thickness of an aquifer and negligibly small slopes. On the other hand, Chapman [10] claims that the storage-discharge relation may vary from linear (for a confined aquifer) to quadratic (for an unconfined flow), which, due to the unavoidable physical limitations of aquifers, suggests the advantage of a linear form over a nonlinear one. This position is supported by Fenicia et al. [11] claiming that nonlinearity, if exists, is an apparent phenomenon resulting from an error caused by groundwater recharge. Kleidon and Savenije [12] use variational principles to show the correctness of the linear model, etc.

From the mathematical point of view this discussion can be reduced to the following question: which curve approximates the recession hydrographs better:

an exponential (linear model) or hyperbolic (nonlinear)? The answer to this question can be obtained by two ways: i) by the optimization of parameters in Eqs. (5) and (8); ii) by the analysis of the following linear relation resulting from Eq. (7):

$$
\ln \left(-\frac{d Q}{d t}\right)=\ln a+b \ln Q
$$

The graphical interpretation of Eq. (10) is known as the Brutsaert and Nieber analysis [13]. The further part of the present paper is focused on some aspects of this procedure (hereinafter called as BN77).

\section{The BN77 analysis - advantages and disadvantages}

A typical example of the BN77 is shown in Fig. 1. The derivatives in Eq. (10) were determined numerically as a finite quotient resulting from the consecutive flow values.

The characteristic feature of the presented graph is the set of dispersed points, i.e. the lack of clearly marked dependence. Brutsaert and Nieber explained this phenomenon by the influence of some disturbing factors, like evapotranspiration, as well as overland flow and quick subsurface flow, and recommended accepting the lower envelope of this set as a basis for determining the recession curve, wherein the envelope is adopted as a line with differentiated slope (i.e. differentiated value of the exponent $b$ ) between initial

\footnotetext{
*Corresponding author: jkurnatowski@ zut.edu.pl
} 
and later phases of the recession. Brutsaert and Nieber were of the following opinion: „This procedure avoids the uncertainty regarding a proper time reference after each rainfall event, and it eliminates the effects of evapotranspiration".

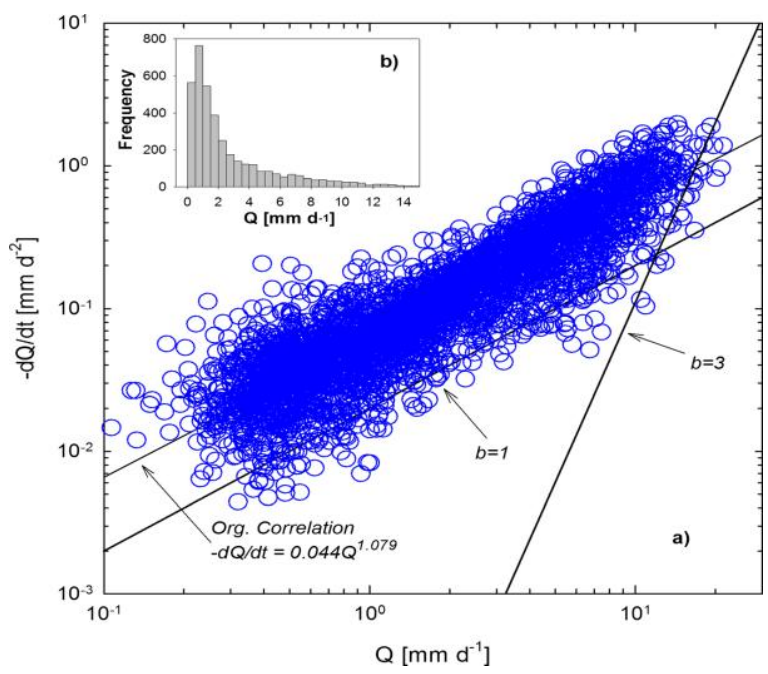

Fig. 1. a) Natural spectrum of data points showing decline in discharge, $-\mathrm{d} Q / \mathrm{d} t\left[\mathrm{~mm} \mathrm{~d}^{-2}\right]$, versus the average discharge, $Q\left[\mathrm{~mm} \mathrm{~d}^{-1}\right]$, during the period 1939-2011 on Lochsa River, Lowell, Idaho. The drainage area is $3,060 \mathrm{~km}^{2}$. The lower envelopes are represented by the lines with slopes $b=1$ and $b=3$. The organic correlation fitting method exhibits a slope of 1.079. b) Shows the distribution of average discharge $Q$ $\left[\mathrm{mm} \mathrm{d}^{-1}\right]$ (reprint with consent of Dr. Sánchez-Murillo [16]).

Analyzing the usefulness of the BN77 method it should be noted that the identification and calibration of the conceptual model of the recession can be carried out in two ways. The first one assumes the solution of the initial problem due to Eqs. (5) and (7) and then the optimization of this solution parameters in order to approach to the best similarity between raw flow data and approximating curve. Following this way requires making the choice of the parameters variability a priori; in practice, these parameters are assumed to be constant. Such a procedure can be risky since the parameters in different phases of the recession may differ from each other. The second way is the BN77 method, which does not require the knowledge of the function $Q(t)$; therefore, can be applied directly on the basis of raw measurement data and avoids assumptions concerning parameters. However, this is a largely apparent advantage, since flow values, generally obtained from the stage-flow relations and requiring measurements of water stages, are subject to an error resulting from a measurement accuracy (independently of errors related to the flow curves construction). The error of flow measurement affects in turn the error of determining its gradient, and the more strongly, the more often the observations are made and the shorter is the period $\Delta t$ between consecutive measurements. On the other hand, lengthening this period reduces the measurement error of the gradient, but increases the numerical error (bias) resulting from the averaging of the gradient value in a given time interval.

As it seems, the impact of such errors on the results of the BN77 analysis has not been sufficiently investigated so far. Although Lamb and Beven [14] mentioned measurement errors as a component of the total error of the analysis, Rupp and Selker [15] criticized the use of fixed intervals $\Delta t$, especially at high flow variability, there is no estimation of the possible magnitude of these errors. In order to make such an estimation a numerical experiment was carried out, simulating a recession curve in a river with a fixed characteristics, and then imposing on this curve errors resulting from inaccurate measurements of stages and creating an appropriate graph of the BN77 method.

\section{Numerical experiment - assumptions and results}

Assumptions for simulation were adopted as follows:

- The flow curve is created on the basis of Chézy and Manning formulas at constant water table slope and constant roughness coefficient;

- Riverbed cross-section is rectangular and wide $\left(R_{\mathrm{h}} \sim h\right)$.

Therefore, the real flow $Q$ can be determined by the relation:

$$
Q=\frac{D \sqrt{5}}{n} \square^{5 / 3}=K \square^{5 / 3},
$$

where $B$ is a riverbed width [m], $S$ - water table longitudinal slope [-], $n$ - roughness coefficient $\left[\mathrm{m}^{-1 / 3} \mathrm{~s}\right], h$ - depth [m]. Introducing the stage (depth) measurement error $\varepsilon$ the measured flow $Q_{1}$ yields:

$$
Q_{1}=K(\square+\varepsilon)^{5 / 3}=K\left[\left(\frac{Q}{R}\right)^{3 / 5}+\varepsilon\right]^{5 / 3} .
$$

The following data set was assumed:

- $K=3.0 \mathrm{~m}^{4 / 3} \mathrm{~s}^{-1}$; this value corresponds e.g. to small lowland river with riverbed width $B=10 \mathrm{~m}$ and slope

$S=0.1 \%$, fairly maintained $(n=0.033)$;

- initial real flow $Q(0)=10.0 \mathrm{~m}^{3} \mathrm{~s}^{-1}$

- the real recession curve is exponential $(b=1)$ with the coefficient $a=0.01 \mathrm{~h}^{-1}$; this value causes a flow reduction of $60 \%$ after approximately 4 days;

- time interval between consecutive stage measurements $\Delta t=2 \mathrm{~h}$.

The error $\varepsilon$ was generated randomly in two ways: first, assuming the extreme possible value $\varepsilon_{\max }= \pm 5$ $\mathrm{mm}$ and applying the probability density function as beta $(3,3)$; second, according to the normal distribution with a standard deviation $\sigma=2.5 \mathrm{~mm}$. The third and fourth options doubled the above values. Considering typical stage measurements carried on at rivers with the

${ }^{\text {* Corresponding author: jkurnatowski@ }}$ zut.edu.pl 
accuracy of $0.01 \mathrm{~m}$, these conditions reflect very high accuracy of stage measurements, far exceeding the practically obtained technical values.

The results of the experiment are given in Fig. 2. The similarity of point cloud between Fig. 1 and graphs in Fig. 2, in particular Fig. 2a) is apparent. In every case the variance of the derivatives values for the given flow increases with decreasing flow; this results from the diminishing differences between consecutive flows and resulting relative influence of errors. The effect of increased slope of the lower envelope at high flows is visible as well, obviously in Fig. 2b), marked with the red line. Evidently, this tendency is not any natural feature of the recession, but results from the diminishing of the variance.

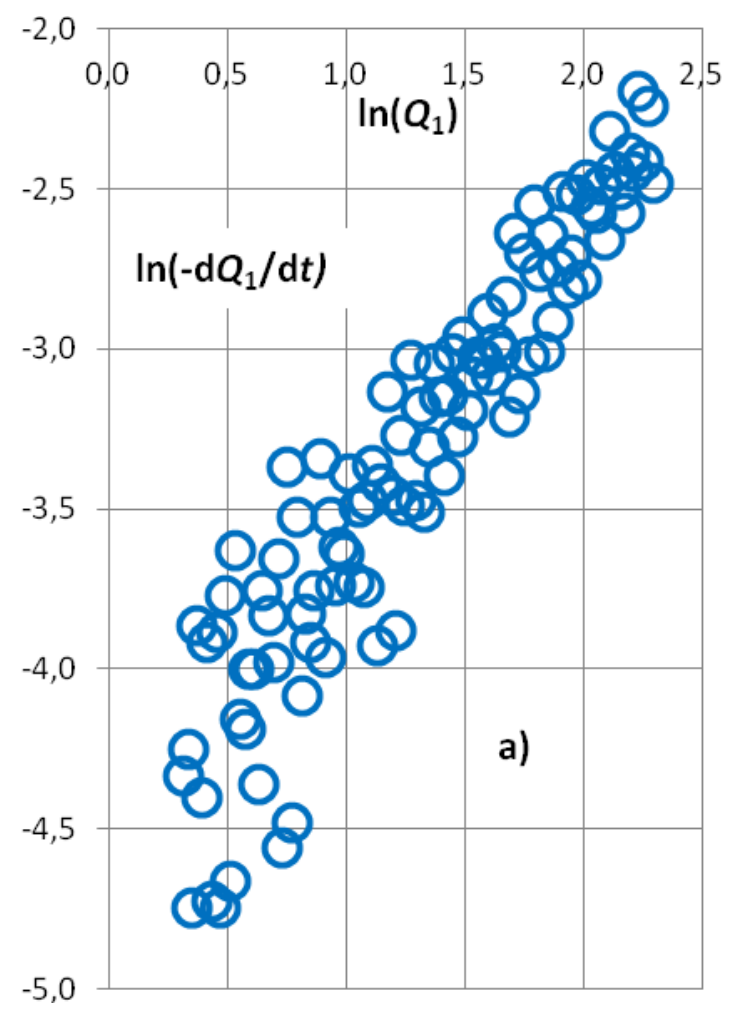

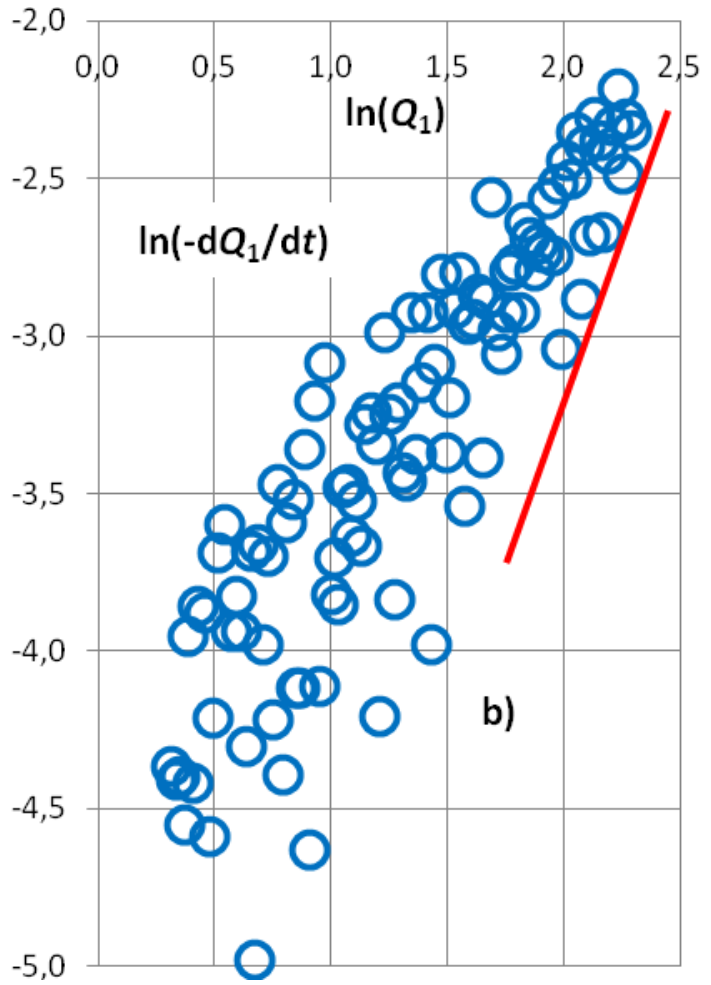

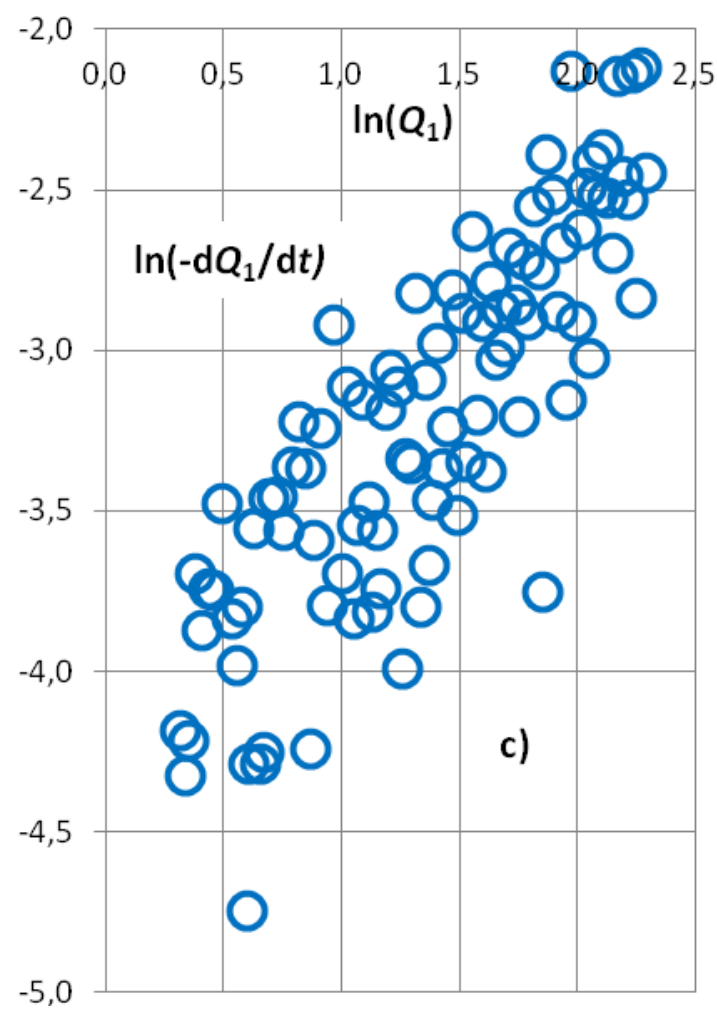

${ }^{\text {* Corresponding author: jkurnatowski@ }}$ zut.edu.pl 


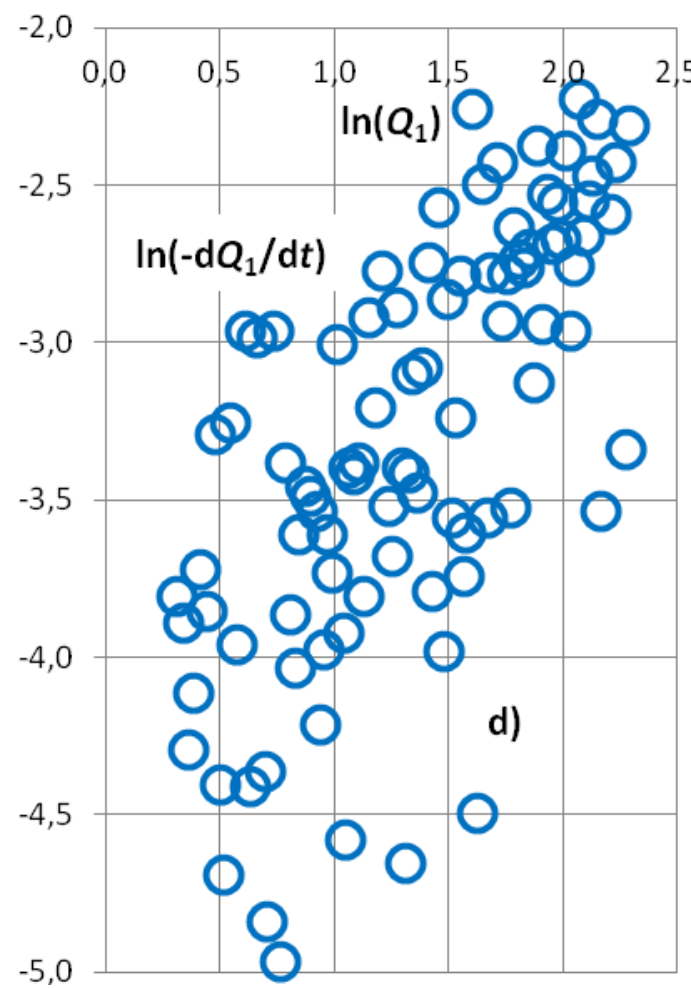

Fig. 2. Results of BN77 analysis of the simulated recession curve with errors subject to: a) beta $(3,3)$ distribution, $\varepsilon_{\max }=0.0050 \mathrm{~m}$; b) normal distribution $\mathrm{N}(0,0.0025 \mathrm{~m})$; c) beta $(3,3)$ distribution, $\varepsilon_{\max }=0.010 \mathrm{~m}$; d) normal distribution, $\mathrm{N}(0,0.0050 \mathrm{~m})$. Red line in b) shows the increasing slope of the lower envelope at high flows.

\section{Conclusions}

The experiment results testify to a high degree the statement about unavoidable impact of measurement errors on the results of the Brutsaert and Nieber analysis of recession curves. Thus, any hydrological interpretations of the variability of flow derivatives (such as the effect of evapotranspiration) should therefore be formulated only after the elimination of flows and flow derivatives errors resulting from measurement errors.

\section{References}

1. L.M. Tallaksen, J. Hydrol. 165, 349-370 (1995)

2. J. Boussinesq, J. Math. Pures Appl. 5(10), 5-78, (1904)

3. P.W. Werner, K.J. Sundquist, IASH General Assembly (Brussels, IAHS Publ. 33, 202-212, 1951)

4. C. Toebes, D.D. Strang, J. Hydrol. N.Z. 3(2), 2-15 (1964)

5. C. Toebes, W.B. Morrissey, R. Shorter, M. Hendy, Handbook of Hydrological Procedures: Procedure No. 8 (A. R. Shearer, Government Printer, Wellington, New Zealand, 1-8, 1969)

6. H. Wittenberg, Hydrol. Process. 13(5), 715-726 (1999)

\footnotetext{
$\overline{{ }^{*} \text { Corresponding author: jkurnatowski@ }}$ zut.edu.pl
}

7. H. Aksoy, H. Wittenberg, Hydrol. Sci. J. 56, 2, 226-237 (2011)

8. M. Ali, A. Fiori, G. Bellotti, Hydrol. Process. 27(18), 2683-2690 (2012)

9. G.H. de Rooij, Hydrol. Earth Syst. Sci. Discuss. 11, 83-108 (2014)

10. T. Chapman, Hydrol. Processes 13, 701-714 (1999)

11. F. Fenicia, H.H.G. Savenije, P. Matgen, L. Pfister, Hydrol. Earth Syst. Sci. 10, 139-150 (2006)

12. A. Kleidon, H.H.G. Savenije, Hydrol. Earth Syst. Sci. Discuss., (in review, 2017)

13. W. Brutsaert, J.L. Nieber, Water Resour. Res. 13, 637-643 (1977)

14. R. Lamb, K.J. Beven, Hydrol. Earth Syst. Sci. 1, 101-113 (1997)

15. D.E. Rupp, J.S. Selker, Adv. Water Resour. 29(2), 154-160 (2006)

16. R. Sánchez-Murillo, E.S. Brooks, W.J. Elliot, E. Gazel, J. Boll, Hydrogeol. J. 23(2), 287-303 (2015) 